\title{
The impact of horizontal heterogeneities, cloud fraction, and liquid water path on warm cloud effective radii from CERES-like Aqua MODIS retrievals
}

\author{
D. Painemal ${ }^{1}$, P. Minnis ${ }^{1}$, and S. Sun-Mack ${ }^{2}$ \\ ${ }^{1}$ NASA Langley Research Center, Hampton, Virginia, USA \\ ${ }^{2}$ Science System and Applications Inc., Hampton, Virginia, USA \\ Correspondence to: D. Painemal (david.painemal@nasa.gov)
}

Received: 25 April 2013 - Published in Atmos. Chem. Phys. Discuss.: 14 May 2013

Revised: 12 August 2013 - Accepted: 5 September 2013 - Published: 11 October 2013

\begin{abstract}
The impact of horizontal heterogeneities, liquid water path (LWP from AMSR-E), and cloud fraction (CF) on MODIS cloud effective radius $\left(r_{e}\right)$, retrieved from the $2.1 \mu \mathrm{m}$ $\left(r_{e 2.1}\right)$ and $3.8 \mu \mathrm{m}\left(r_{e 3.8}\right)$ channels, is investigated for warm clouds over the southeast Pacific. Values of $r_{e}$ retrieved using the CERES algorithms are averaged at the CERES footprint resolution $(\sim 20 \mathrm{~km})$, while heterogeneities $\left(H_{\sigma}\right)$ are calculated as the ratio between the standard deviation and mean $0.64 \mu \mathrm{m}$ reflectance. The value of $r_{e 2.1}$ strongly depends on $\mathrm{CF}$, with magnitudes up to $5 \mu \mathrm{m}$ larger than those for overcast scenes, whereas $r_{e 3.8}$ remains insensitive to CF. For cloudy scenes, both $r_{e 2.1}$ and $r_{e 3.8}$ increase with $H_{\sigma}$ for any given AMSR-E LWP, but $r_{e 2.1}$ changes more than for $r_{e 3.8}$. Additionally, $r_{e 3.8}-r_{e 2.1}$ differences are positive $(<1 \mu \mathrm{m})$ for homogeneous scenes $\left(H_{\sigma}<0.2\right)$ and LWP $>45 \mathrm{gm}^{-2}$, and negative (up to $-4 \mu \mathrm{m}$ ) for larger $H_{\sigma}$. While $r_{e 3.8}-r_{e 2.1}$ differences in homogeneous scenes are qualitatively consistent with in situ microphysical observations over the region of study, negative differences - particularly evinced in mean regional maps - are more likely to reflect the dominant bias associated with cloud heterogeneities rather than information about the cloud vertical structure. The consequences for MODIS LWP are also discussed.
\end{abstract}

\section{Introduction}

Cloud optical thickness $(\tau)$ and effective radius $\left(r_{e}\right)$ derived from visible and near-infrared satellite instruments have become the standard observational data set in cloud- atmospheric research. The availability of these parameters at high temporal and spatial resolution over the globe over long time periods makes them particularly suitable for climate studies (e.g., Stubenrauch et al., 2013). Among several practical simplifications that make the inverse problem of determining $r_{e}$ and $\tau$ tractable is the assumption that clouds are horizontally homogeneous (plane-parallel) objects. Nevertheless, the effect of neglecting the cloud 3-D structure and the associated radiative fields can be a significant source of retrieval error (Marshak et al., 2006). Given this uncertainty, there is an increasing interest in understanding how the 3-D radiative effects can obscure the physical insight gained from satellite observations.

Multi-spectral instruments such as the MODerate resolution Imaging Spectroradiometer (MODIS) offer practical ways to explore 3-D related artifacts in the retrievals. Since 3 -D radiative effects are wavelength dependent, the use of three MODIS $r_{e}$ retrievals from the 1.6, 2.1, and $3.8 \mu \mathrm{m}$ channels provides a simple framework to explore biases in the observations (e.g., Zhang and Platnick, 2011). Although in principle $r_{e}$ retrieved at $3.8 \mu \mathrm{m}$ is less sensitive to planeparallel biases and 3-D radiative effects, determining the effects of cloud heterogeneities with the use of multispectral $r_{e}$ retrievals is difficult as the different photon penetration of the three MODIS channels in theory should also capture physical information of the cloud vertical structure (Platnick, 2000). This implies that the $3.8 \mu \mathrm{m}$-based $r_{e}$ is more influenced by properties closer to the cloud top than the 2.1 and $1.6 \mu \mathrm{m}$ counterparts. 
In this contribution, we explore the ways that cloud properties retrieved from Aqua MODIS radiances vary for different cloud dynamical configurations and spatial heterogeneities at spatial resolutions typical of synoptic/climate studies. The goal here is to determine the bias magnitude in $r_{e}$ due to heterogeneities as well as understanding the physical information that can be obtained from $r_{e}$ differences calculated at two wavelengths (3.8 and $2.1 \mu \mathrm{m}$ ).

\section{Data set}

Here we use values of $\tau$ and $r_{e}$ retrieved from Aqua MODIS data using algorithms that will be used to generate the Clouds and Earth's Radiant Energy System (CERES) Edition-4 products and averaged in the same manner as the CERES Single Scanner Footprint (SSF) product (CERES, 2012) to create a pseudo-SSF (hereafter PSSF). The Edition-4 algorithm changes relative to the CERES Edition-2 techniques (Minnis et al., 2011a) are mostly summarized by Minnis et al. (2010). The cloud parameters are derived from $1 \mathrm{~km}$ MODIS radiances sampled every other scan line and fourth element, and convolved with the CERES instrument point spread function to produce averages and standard deviations that match the CERES instrument footprint $(\sim 20 \mathrm{~km}$ at nadir). The PSSF used here includes several hundred parameters including averages and standard deviations of the MODIS radiances, $\tau$ retrieved at $0.64 \mu \mathrm{m}$, and three $r_{e}$ values retrieved from the 1.2, 2.1, and 3.8 $\mu \mathrm{m}$ MODIS channels. The multispectral retrievals for $r_{e}$ use the same method as that described by Minnis et al. (2011) to obtain $r_{e}$ at $3.8 \mu \mathrm{m}$, $r_{e 3.8}$, except that the 1.2 and $2.1 \mu \mathrm{m}$ reflectances substitute for the $3.8 \mu \mathrm{m}$ brightness temperatures in the iterative solution to yield $r_{e 1.2}$ and $r_{e 2.1}$, respectively. In this investigation we only use the 3.8 and $2.1 \mu \mathrm{m}$-based $r_{e}$, because they have proven to yield contrasting sensitivities to both the cloud vertical and horizontal structure (Platnick, 2000; Zhang and Platnick, 2011). The $1.2 \mu \mathrm{m}$-based $r_{e}$ retrieval is still experimental and will require further evaluation before being used for scientific analyses. Cloud fraction (CF) is also convolved from the clear and cloudy MODIS pixels within each CERES footprint. Although the CERES cloud algorithm differs from that of the MODIS Atmospheres team (Platnick et al., 2005), both results agree well for $r_{e 3.8}$, with some small differences mainly explained by the tendency of the MODIS team Collection 5 retrievals to discard pixels with very thin clouds or near the cloud edges in broken scenes (Minnis et al., 2011b). Figure 1a shows the mean CERES $r_{e 3.8}$ (colors) and $\Delta r_{e}=$ $r_{e 3.8}-r_{e 2.1}$ (contours) during the period of study. The $r_{e 3.8}$ values agree with MODIS team counterpart in Zhang and Platnick (2011) and Nakajima et al. (2010), in terms of magnitude and westward gradient. Moreover, as in the MODIS team retrievals, $r_{e 2.1}$ is generally larger than $r_{e 3.8}$, with a westward increase of $\left|\Delta r_{e}\right|$ (Fig. 1a, contours), consistent with larger liquid water paths as well (O’Dell et al., 2008).
These features are also common to other marine stratocumulus regimes (Zhang and Platnick, 2011).

We computed a heterogeneity index $H_{\sigma}$, defined as the ratio of the standard deviation to the mean MODIS $0.64 \mu \mathrm{m}$ at $1 \mathrm{~km}$ reflectance at the PSSF resolution $(\sim 20 \mathrm{~km}$ at nadir $)$ using the $1 \times 4$ sampling of the PSSF. We note that $H_{\sigma}$ defined here differs from that in Liang et al. (2009), which was calculated at a $1 \mathrm{~km}$ resolution from the $250 \mathrm{~m}$ and $0.86 \mu \mathrm{m}$ MODIS reflectances. While the $1 \mathrm{~km} H_{\sigma}$ is more adequate for studying 3-D radiative effects, the use of a coarser $H_{\sigma}$, along with spatially averaged $r_{e}$, is relevant for determining how spatial heterogeneities might bias the retrievals at typical resolutions used in regional/climate studies. Our assumption here is that heterogeneities at sub-pixel scale also manifest at macroscopic scales, such as that of the CERES footprint resolution. In other words, the cloud retrievals' dependence on the CERES-scale $H_{\sigma}$ reported in this study mostly emerges from the pixels' internal variability $(<1 \mathrm{~km})$.

Finally, as explained in Painemal et al. (2012), in order to create regular-grid maps, we spatially average the PSSF variables to a resolution of $0.5^{\circ}$ (each new grid contains at least one PSSF near the scan edge).

Independent liquid water path (LWP) retrievals are from the Advanced Microwave Scanning Radiometer-EOS, AMSR-E (Wentz and Meissner, 2000), and spatially averaged to a $0.5^{\circ}$ spatial resolution from the $0.25^{\circ}$ native resolution. In order to minimize precipitation biases in AMSRE LWP, we limited our analysis to clouds with $L W P<$ $150 \mathrm{~g} \mathrm{~m}^{-2}$. While this threshold screens cases with moderate and heavy precipitation, it still allows cloud sampling with light precipitation and drizzle (e.g., Leon et al., 2008; Kubar et al., 2009; Painemal and Zuidema, 2011).

As in Zhang and Platnick (2011), our focus is on the marine stratocumulus regime of the southeast Pacific, defined here as encompassing the oceanic area within the bounds $100-70^{\circ} \mathrm{W}$ and $33-5^{\circ} \mathrm{S}$. We analyze 15 months of daily satellite passes from 2002 to 2004 during the AugustDecember period, when the cloud deck is at its maximum spatial development. The solar zenith angles between $20^{\circ}$ and $35^{\circ}$ allow us to isolate the effect of cloud heterogeneities from the solar zenith angle influence in the retrievals, especially for very oblique angles (Kato and Marshak, 2009).

\section{Brief description of the microphysical features during VOCALS-REx}

An advantage of limiting our study to the southeast Pacific Ocean is that we can exploit the improved microphysical understanding gained from the VAMOS OceanCloud-Atmosphere-Land Study (VOCALS) Regional Experiment (Mechoso et al., 2013). Specifically, more than 100 cloud vertical samples over the $19-30^{\circ} \mathrm{S}$ and $85-71^{\circ} \mathrm{W}$ domain, collected during October-November of 2008, reveal in great detail the cloud microphysical structure of the 
marine stratocumulus clouds. In situ observations of westward increases in both $r_{e}$ and LWP were typical during VOCALS-REx, and connected with a boundary layer deepening and more drizzle occurrence. These zonal changes are qualitatively well reproduced by retrievals using MODIS data (Painemal and Minnis, 2012; Brunke et al., 2010). In terms of the vertical structure, in situ observations also yield a robust pattern, in which $r_{e}$ monotonically increases toward the cloud top, regardless of the magnitude of LWP (Fig. 5 in Painemal and Zuidema, 2011). Although precipitation can modify the $r_{e}$ profile, the droplet size tends to peak at the cloud top even for clouds with LWP as large as $250 \mathrm{gm}^{-2}$ (Painemal and Zuidema, 2011). The cloud vertical structure observed during VOCALS-REx has interesting similarities with other field campaigns. For instance, droplet measurements in shallow cumuli collected during the Rain In $\mathrm{Cu}$ mulus over the Ocean field experiment also evince a maximum $r_{e}$ near the cloud top (Arabas et al., 2009). The fact that the particle size seems to be unaffected by cloud top entrainment indicates that the mixing is mostly homogeneous. That is, the evaporation timescale is faster than the mixing scale (Lehmann et al., 2009).

In the context of MODIS satellite retrievals, if the source of difference between $r_{e 2.1}$ and $r_{e 3.8}$ arises exclusively from the cloud vertical inhomogeneity unaccounted for in the algorithm, then expectations built upon aircraft observations should be that $r_{e 3.8}>r_{e 2.1}$, as discussed in Platnick (2000).

\section{Cloud fraction and heterogeneity}

Mean $H_{\sigma}$ shows typical values between 0.1 and 0.4 , with increasing heterogeneities westward (Fig. 1b). As expected, $H_{\sigma}$ and CF spatially co-vary, with a decrease in cloud fraction generally concomitant with larger $H_{\sigma}$. The spatial similarities between $r_{e}, \Delta r_{e}, H_{\sigma}$, and CF motivate a more detailed inspection of the factors that control $\Delta \mathrm{r}_{e}$.

The histogram in Fig. 2a shows that the scene heterogeneity tends to increase with $\mathrm{CF}$ until $\mathrm{CF}$ reaches $60 \%$. For higher $\mathrm{CFs}, H_{\sigma}$ is anti-correlated with $\mathrm{CF}$, whereas for nearly overcast scenes, the liquid water path modulates $H_{\sigma}$, as shown in the following sections. Figure $2 \mathrm{~b}$ and $\mathrm{c}$ depict the binned values of $r_{e 3.8}$ and $r_{e 2.1}$ as functions of CF and $H_{\sigma}$. As expected, the general trend is that both $r_{e 3.8}$ and $r_{e 2.1}$ increase with $H_{\sigma}$, reaching their largest magnitude for $H_{\sigma}=0.4$. Nevertheless, both retrievals show dissimilar sensitivities to changes in CF. While $r_{e 3.8}$ is insensitive to $\mathrm{CF}$ variations, $r_{e 2.1}$ decreases with $\mathrm{CF}$, with radii between 12 and $17 \mu \mathrm{m}$ for a fixed $H_{\sigma}=0.2$. It can also be seen that the $r_{e 3.8}-r_{e 2.1}$ difference $\left(\Delta r_{e}\right)$ is near $-6 \mu \mathrm{m}$ for $H_{\sigma}<0.15$ and $\mathrm{CF}=40 \%$, whereas this is reduced to around -1 to $-2 \mu \mathrm{m}$ for overcast scenes only. These results strongly support the observations made by Zhang and Platnick (2011) for a limited number of overcast and broken MODIS granules. The values of $\Delta r_{e}$, as a function of CF and $H_{\sigma}$, are in agree- ment with the smaller impact of 3-D radiative transfer and sub-pixel variability on $r_{e 3.8}$ than on $r_{e 2.1}$, although the negligible impact of $\mathrm{CF}$ on $r_{e 3.8}$ is surprising.

\section{Heterogeneity and AMSR-E liquid water path in cloudy scenes}

For cloudy scenes, when $\mathrm{CF}>98 \%$, an LWP-dependent analysis is relevant because one should expect a relationship between LWP, $H_{\sigma}$, and the cloud vertical structure. LWP has been recognized as a cloud macrophysical property (e.g., Wood, 2012), as it is the manifestation of different forcing parameters, such as sea surface temperature, divergence, humidity, and atmospheric stability (e.g., Stevens and Brenguier, 2009). LWP and in-cloud turbulence (updrafts) are linked because an LWP increase produces stronger cloud top radiative cooling, which in turn favors the turbulence production. Moreover, increasing LWP associated with boundary layer deepening (e.g., Painemal et al., 2013) should facilitate droplet size condensational growth. All these factors modify the cloud droplet activation and growth, affecting the droplet size, the vertical structure, and drizzle generation. The use of LWP as a proxy for the cloud dynamics has also been applied for isolating the cloud-aerosol interactions from those factors associated with the regional circulation and cloud dynamics (e.g., McComiskey and Feingold, 2012, and references therein).

To tackle the problem of untangling the heterogeneity bias from the physical information, we use AMSR-E LWP, a retrieval that is nearly insensitive to 3-D radiative transfer effects for the clouds investigated in this work. Similar to the approach in Sect. 4, we binned the MODIS retrievals as functions of both $H_{\sigma}$ and AMSR-E LWP. Figure 3a shows the dual dependence of $r_{e 3.8}$ on $H_{\sigma}$ and LWP. Irrespective of $H_{\sigma}$, $r_{e 3.8}$ increases with LWP, which is consistent with condensational growth and more active collision and coalescence when water content increases. In addition, $r_{e 3.8}$ increases with $H_{\sigma}$ are also apparent, in agreement with other studies (Zhang and Platnick, 2011). The magnitude of the change in $r_{e 3.8}$ with $H_{\sigma}$ is confined to $3-4 \mu \mathrm{m}$ for any given LWP bin.

Differences between $r_{e 3.8}$ and $r_{e 2.1}$ are depicted in Fig. 3b. The largest differences, near $4 \mu \mathrm{m}$, are observed for the most heterogeneous cases, irrespective of LWP. For $H_{\sigma}=0.1$, $\Delta r_{e}$ is small but positive for $\mathrm{LWP}>45 \mathrm{~g} \mathrm{~m}^{-2}(\sim 0.8 \mu \mathrm{m}$ for $\left.\mathrm{LWP}=125 \mathrm{~g} \mathrm{~m}^{-2}\right)$. This result is remarkable as it agrees with in situ observations (Sect. 3) in stratocumulus clouds, for different magnitudes of in situ LWP, including light precipitating events (Painemal and Zuidema, 2011). The physical consistency between MODIS retrievals builds confidence in the utility of the cloud retrievals for representing general aspects of the cloud vertical structure within homogeneous cloud scenes. Finally, Fig. 3c shows the expected decrease of $\tau$ with increasing $H_{\sigma}$, as well as the optical thickening with increasing LWP. 
Table 1. MODIS fractional changes relative to fractional changes in $H_{\sigma}$, Eq. (2).

\begin{tabular}{lrrrr}
\hline & $m_{\text {LWP } \kappa}$ & $m_{r \kappa}+m_{\tau}$ & $m_{r \kappa}$ & $m_{\tau}$ \\
\hline$\kappa=3.8$ & -0.29 & -0.27 & 0.17 & -0.44 \\
$\kappa=2.1$ & -0.13 & -0.10 & 0.34 & \\
\hline
\end{tabular}
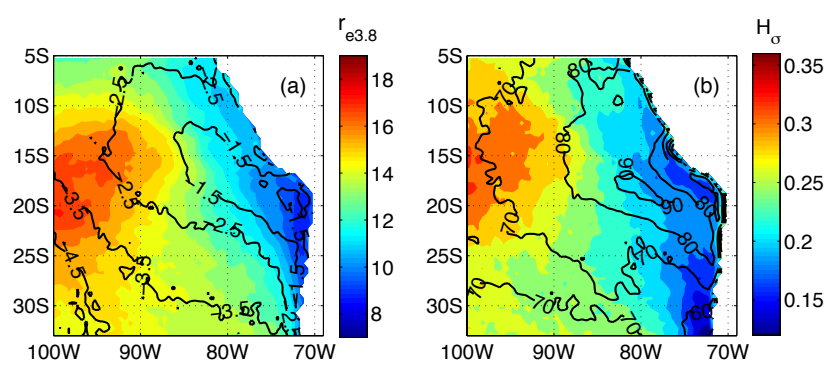

Fig. 1. Average fields during the period of study: (a) $r_{e 3.8}$ (color) and $\Delta r_{e}=r_{e 3.8}-r_{e 2.1}$ (contours), (b) $H_{\sigma}$ (colors) and cloud fractions (contours). The continent is represented by the white region.

\section{Revisiting the impact of $H_{\sigma}$ on MODIS liquid water path}

Because the product of $r_{e}$ and $\tau$ can be used to estimate LWP, we center our focus on LWP. Here, we express the MODIS LWP by assuming a cloud having a vertical increase of water content and $r_{e}$ with height:

MODISLWP $=\frac{5}{9} \rho_{\mathrm{w}} \cdot r_{e} \cdot \tau$,

where $\rho_{\mathrm{w}}$ denotes the density of the liquid water. LWP in Eq (1) is 5/6 the magnitude of that calculated for a vertically homogeneous cloud, and it is adopted here because it yields better agreement with microwave estimates and in situ observations (Seethala and Horvath, 2010; Painemal et al., 2012).

Given the westward gradients in $\Delta r_{e}$ and $H_{\sigma}$ observed in Fig. 1, we analyze further the impact of using $r_{e 3.8}$ and $r_{e 2.1}$ in the computation of MODIS LWP (Eq. 1), in the context of spatial heterogeneities. Figure $4 \mathrm{a}$ and $\mathrm{b}$ show histograms for the biases between AMSR-E and MODIS LWP, for a $4^{\circ} \times 3^{\circ}$ coastal (centered at $76.75^{\circ} \mathrm{W}, 23.75^{\circ} \mathrm{S}$ ) and offshore (centered at $97.75^{\circ} \mathrm{W}, 23.75^{\circ} \mathrm{S}$ ) region, respectively. The blue histogram indicates LWP differences calculated using daily $r_{e 3.8}\left(\mathrm{LWP}_{3.8}\right)$, whereas its red counterpart makes use of $r_{e 2.1}\left(\mathrm{LWP}_{2.1}\right)$. Coastal histograms (Fig. 4a) show a narrow distribution, in part because LWP tends to be small near the coast. In addition, the histograms do not suggest meaningful differences between AMSR-E and MODIS retrievals, whether they are calculated with $\mathrm{LWP}_{3.8}$ or $\mathrm{LWP}_{2.1}$ (mean biases -7.5 and $-5.6 \mathrm{gm}^{-2}$ ). In contrast, offshore histograms (Fig. 4b) are broader, with a shift toward larger positive bias for $\mathrm{LWP}_{\mathrm{AMSR}-\mathrm{E}}-\mathrm{LWP}_{3.8}$ relative to $\mathrm{LWP}_{\mathrm{AMSR}-\mathrm{E}^{-}}$ LWP $_{2.1}$. The mean AMSR-E/MODIS biases are 9.6 and

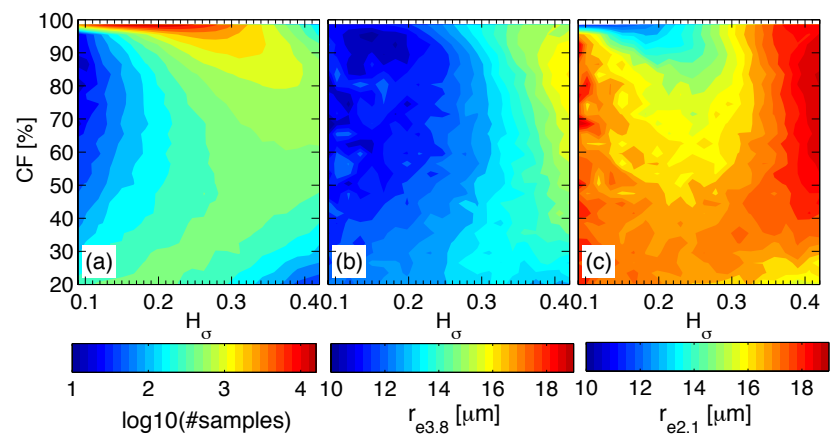

Fig. 2. (a) Number of samples contained in each $H_{\sigma}-\mathrm{CF}$ bin (logarithmic scale), (b) mean $r_{e 3.8}$ for each $H_{\sigma}-\mathrm{CF}$ bin, (c) same as Fig. $1 \mathrm{~b}$ but for $r_{e 2.1}$. The bin sizes are $3 \%$ and 0.016 for $\mathrm{CF}$ and $H_{\sigma}$, respectively.

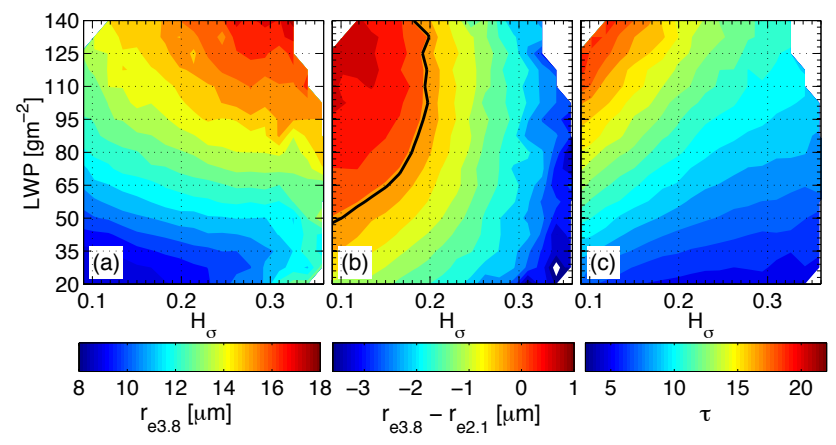

Fig. 3. Binned values for cloudy scenes ( $\mathrm{CF}>98 \%$ ) as a function of $H_{\sigma}$ and AMSR-E LWP: (a) $r_{e 3.8}$, (b) $\Delta \mathrm{r}_{e}=r_{e 3.8}-r_{e 2.1}$, with zero values denoted by the black contour, and (c) $\tau$. The bin sizes are 0.016 and $7.5 \mathrm{gm}^{-2}$ for $\mathrm{CF}$ and $H_{\sigma}$, respectively. Bins constructed with less than 30 samples were excluded.

$1.4 \mathrm{gm}^{-2}$ for $\mathrm{LWP}_{3.8}$ and $\mathrm{LWP}_{2.1}$, respectively. Interestingly, the differences between Fig. $4 \mathrm{a}$ and $\mathrm{b}$ are accompanied by contrasting changes in $H_{\sigma}$ (Fig. 4c). Coastal and offshore regions yield distinctive values of $H_{\sigma}$, with a distribution mode of 0.15 for coastal clouds (Fig. 4c, gray line), and 0.25 for far offshore clouds (black line). The MODIS LWP and $H_{\sigma}$ relationship is further emphasized in Fig. 4d, where mean $H_{\sigma}$ values and the mean differences between $\mathrm{LWP}_{3.8}$ and $\mathrm{LWP}_{2.1}$ are shown as a function of longitude. The $\mathrm{LWP}_{3.8}-$ $\mathrm{LWP}_{2.1}$ zonal gradients are concomitant with $H_{\sigma}$ increases, indicating a distinctive bias compensation between both $r_{e}$ values and $\tau$ to changes in heterogeneities. We explore this idea in more detail by taking averages of all the binned MODIS variables over the study region (constructed from LWP AMSR-E) as a function of $H_{\sigma}$ bins. The results in Fig. 5a reveal a close match between $r_{e 2.1}$ and $r_{e 3.8}$ for homogeneous cases and a greater increase of $r_{e 2.1}$ with $H_{\sigma}$ (black and red lines). The decreases in MODIS LWP with $H_{\sigma}$ in Fig. 5b are more dramatic for $\mathrm{LWP}_{3.8}$. Here, the AMSR-E LWP is constant at $80 \mathrm{~g} \mathrm{~m}^{-2}$ by design. 

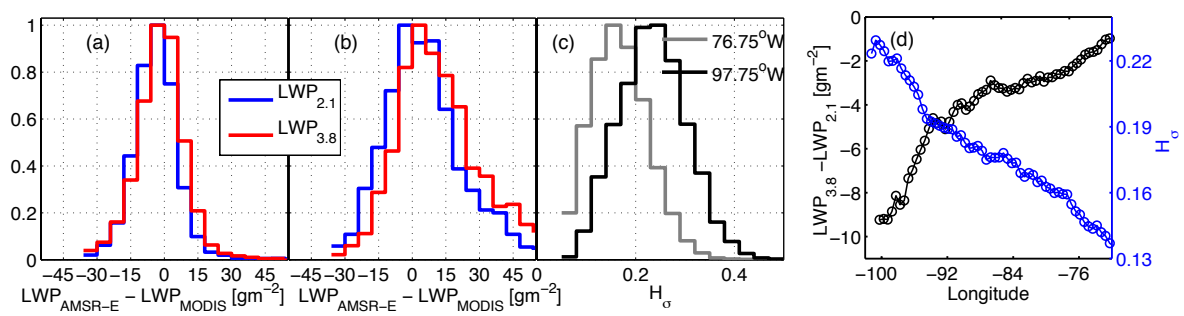

Fig. 4. Normalized histograms for the differences between AMSR-E and MODIS LWP for two $4^{\circ} \times 3^{\circ}$ regions: (a) coastal area centered at $76.75^{\circ} \mathrm{W}, 23.75^{\circ} \mathrm{S}$, and (b) offshore area centered at $97.75^{\circ} \mathrm{W}, 23.75^{\circ} \mathrm{S}$. Red and blue histograms correspond to $\mathrm{LWP}_{\mathrm{AMSR}-\mathrm{E}}-\mathrm{LWP}_{3.8}$ and LWP $\mathrm{AMSR}_{\mathrm{E}}-\mathrm{LWP}_{2.1}$, respectively. (c) Normalized $H_{\sigma}$ histograms for the coastal (gray) and offshore (black) regions in (a) and (b). (d) Mean westward variation of $H_{\sigma}$ (blue) and $\mathrm{LWP}_{3.8}-\mathrm{LWP}_{2.1}$ along $21.25-26.25^{\circ} \mathrm{S}$. Figures are constructed from cloudy scenes only $(\mathrm{CF}>98 \%)$.
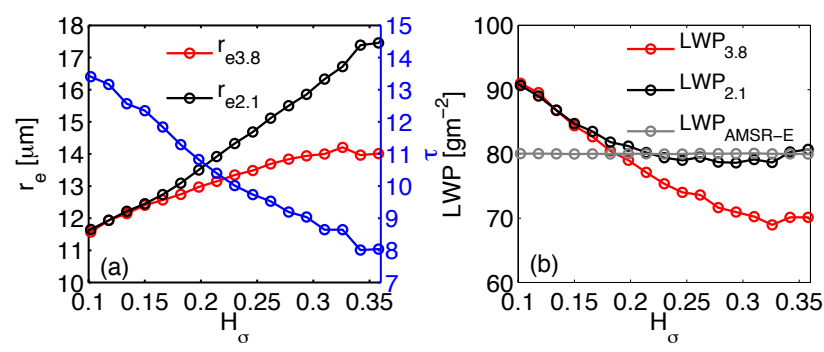

Fig. 5. (a) Mean $r_{e 3.8}, r_{e 2.1}$, and $\tau$ binned by AMSR-E LWP and $H_{\sigma}$, and subsequently averaged for all LWP bins (red, black, and blue lines, respectively) for cloudy scenes only ( $\mathrm{CF}>98 \%)$. (b) As in (a), but for LWP (AMSR-E LWP is constant at $80 \mathrm{~g} \mathrm{~m}^{-2}$ by design).

We quantify the influence of $H_{\sigma}$ by analyzing fractional changes of MODIS LWP relative to fractional changes in $H_{\sigma}$, $\frac{\partial \ln \left(\mathrm{LWP}_{\kappa}\right)}{\partial \ln \left(H_{\sigma}\right)}$, with $\kappa=3.8,2.1$. It follows from Eq. (1) that

$\underbrace{\frac{\partial \ln \left(\mathrm{LWP}_{\kappa}\right)}{\partial \ln \left(H_{\sigma}\right)}}_{m_{\mathrm{LWP}_{\kappa}}}=\underbrace{\frac{\partial \ln \left(r_{e \kappa}\right)}{\partial \ln \left(H_{\sigma}\right)}}_{m_{r_{\kappa}}}+\underbrace{\frac{\partial \ln (\tau)}{\partial \ln \left(H_{\sigma}\right)}}_{m_{\tau}}$,

where $m_{\mathrm{LWP}, \kappa}, m_{r \kappa}$, and $m_{\tau}$ in Eq. (2) are calculated as the slopes of the natural logarithm of the curves in Fig. 5a and $\mathrm{b}$ and are listed in Table 1. As a consistency check, we compared the calculated left- and right-hand sides in Eq. (2) and found that the combined $r_{e}$ and $\tau$ slopes deviate by less than $24 \%$ from those for LWP. In terms of the $r_{e}$ slopes, $m_{r 3.8}$ is smaller than $m_{r 2.1}(0.34)$ by $50 \%$. The dominant dependence of LWP on $\tau$ and the negative sign of the $\ln (\tau)-$ $\ln \left(H_{\sigma}\right)$ slope $\left(m_{\tau}=-0.44\right)$ explains why the MODIS LWP decreases with $H_{\sigma}$, and the LWP bias decreases and changes sign with AMSR-E LWP (Figs. 5b and 4, respectively). The values in Table 1 also help explain why changes in $\mathrm{LWP}_{2.1}$ with $H_{\sigma}$ are smaller than those for $\mathrm{LWP}_{3.8}$.

\section{Conclusions}

Motivated by studies that support both the physical and the 3-D radiative interpretation of the differences in $r_{e}$ values derived from the 3.8 and $2.1 \mu \mathrm{m}$ MODIS data, we endeavored to understand the contribution of LWP and $H_{\sigma}$ to the $\Delta r_{e}$ variability. Homogeneous clouds have larger values of $r_{e 3.8}$ relative to $r_{e 2.1}$, indicating a physical increase of $r_{e}$ toward the cloud top and a negligible effect of precipitation in the retrievals. Our results are consistent with aircraft observations of cloud microphysics over the region of study, which show an adiabatic-like cloud behavior (Painemal and Zuidema, 2011). The current study also shows that the use of $\Delta r_{e}$ for microphysical studies without knowledge of $H_{\sigma}$ is insufficient for determining vertical features of the cloud. Moreover, because $H_{\sigma}$ is typically large in cumulus clouds, they will continue to pose a formidable challenge for passive remote sensing. Overall, we conclude that $\Delta r_{e}$ is more suitable as a metric to investigate cloud heterogeneities rather than the cloud physical structure in marine stratocumulus clouds.

A result of interest for cloud-aerosol interaction studies is the lack of sensitivity of $r_{e 3.8}$ to CF. Although a weaker dependence of $r_{e 3.8}$ on $\mathrm{CF}$ is expected from the reduced photon vertical penetration at $3.8 \mu \mathrm{m}$ and from the smaller sensitivity to sub-pixel variability (plane-parallel bias) than retrievals at $2.1 \mu \mathrm{m}$, the negligible dependence of $r_{e 3.8}$ on CF is rather unexpected. We hypothesize that this is related to the fact that our observations are $0.5^{\circ} \times 0.5^{\circ}$ averages, which allow further error cancellation (e.g., Marshak et al., 2006). We recommend caution when using $r_{e 2.1}$ combined with nearly collocated aerosol optical thickness, especially if broken clouds dominate the $r_{e}$ retrieval scenes. A similar problem might arise if variability in $r_{e 2.1}$ is analyzed as a function of meteorological factors, since they are likely to be correlated with cloud cover variability (e.g., Lebsock et al., 2008).

The problem of determining errors in MODIS-based LWP is difficult because of the dissimilar responses of $r_{e}$ and $\tau$ to changes in cloud heterogeneities. Our results also provide interpretation of the AMSR-MODIS LWP bias correlation with 
$\Delta r_{e}$ reported by Seethala and Horvath (2010). The smaller values of MODIS LWP relative to the AMSR-E values, when $r_{e 2.1}$ greatly exceeds $r_{e 3.8}$, are associated with the rapid decrease of $\tau$ with $H_{\sigma}$ (relative to homogeneous scenes with the same AMSR-E LWP) that tends to occur with rising AMSRE LWP. It is still puzzling why the MODIS LWP is slightly larger than AMSR-E LWP for highly homogeneous cases. A plausible cause might be linked to the thermal emission underestimation within the AMSR-E LWP algorithm (Seethala and Horvath, 2010), although unexplained overestimates of MODIS $r_{e}$ relative to in situ observations (Painemal and Zuidema, 2011) might also contribute to overestimates of MODIS LWP relative to AMSR-E LWP.

Finally, while this analysis is only valid for clouds with LWP $<150 \mathrm{gm}^{-2}$, our results can help by determining the minimum thresholds by which $r_{e 3.8}-r_{e 2.1}$ differences might potentially indicate physical information about the cloud vertical structure. As suggested by Figs. 5a and 3b, we speculate that $\Delta r_{e}$ differences in cloudy scenes must at least surpass $|-4.0 \mu \mathrm{m}|$ (the largest differences for the most heterogeneous scenes) to be plausibly considered as physical rather than biases due to sub-pixel variability. This threshold would imply that, on average, values of $r_{e 2.1}$ exceeding $18 \mu \mathrm{m}$ over oceanic regions (Fig. 3 in Nagao et al., 2013) along with $r_{e 2.1}>\left(r_{e 3.8}+4 \mu \mathrm{m}\right)$ might be indicative of the actual effect of precipitation on $r_{e}$, which would tend to increase droplet size toward the cloud base.

Acknowledgements. D. Painemal was supported by the NASA Postdoctoral Program at the NASA Langley Research Center. P. Minnis and S. Sun-Mack were supported by the NASA Modeling, Analysis, and Prediction and CERES Programs. The CERES-like PSSF data were processed at the NASA Earth Observing System Data and Information System, Langley Research Center Atmospheric Sciences Data Center. AMSR-E data are produced by Remote Sensing Systems and sponsored by the NASA Earth Science MEaSUREs DISCOVER Project and the AMSR-E Science Team. Data are available at www.remss.com.

Edited by: J. Quaas

\section{References}

Arabas, S., Pawlowska, H., and Grabowski W. W.: Effective radius and droplet spectral width from in-situ aircraft observations in trade-wind cumuli during RICO, Geophys. Res. Lett., 36, L11803, doi:10.1029/2009GL038257, 2009.

Brunke, M. A., de Szoeke, S. P., Zuidema, P., and Zeng, X.: A comparison of ship and satellite measurements of cloud properties with global climate model simulations in the southeast Pacific stratus deck, Atmos. Chem. Phys., 10, 6527-6536, doi:10.5194/acp-10-6527-2010, 2010.

CERES: Single scanner footprint TOA/surface fluxes and clouds (SSF), CERES Data Products Catalog, DPC-SSF-Ed4 R5V, 16 pp., 2012.
Kato, S. and Marshak, A.: Solar zenith and viewing geometrydependent errors in satellite retrieved cloud optical thickness: Marine stratocumulus case, J. Geophys. Res., 114, D01202, doi:10.1029/2008JD010579, 2009.

Kubar, T., Hartmann, D. L., and Wood, R.: Understanding the importance of microphysics and macrophysics for warm rain in marine low clouds. Part I: Satellite observations, J. Atmos. Sci., 66, 2953-2972, doi:10.1175/2009JAS3071.1, 2009.

Lebsock, M. D., Stephens, G. L, and Kummerow, C: Multisensor satellite observations of aerosol effects on warm clouds, J. Geophys. Res., 113, D15205, doi:10.1029/2008JD009876, 2008.

Lehmann, K., Siebert, H., and Shaw, R. A.: Homogeneous and inhomogeneous mixing in cumulus clouds: Dependence on local turbulence structure, J. Atmos. Sci., 66, 3641-3659, 2009.

Leon, D. C., Wang, Z., and Liu, D.: Climatology of drizzle in marine boundary layer clouds based on 1 year of data from CloudSat and Cloud- Aerosol Lidar and Infrared Pathfinder Satellite Observations (CALIPSO), J. Geophys. Res., 113, D00A14, doi:10.1029/2008JD009835, 2008.

Liang, L., Di Girolamo, L., and Platnick, S.: View-angle consistency in reflectance, optical thickness and spherical albedo of marine water-clouds over the northeastern Pacific through MISR-MODIS fusion, Geophys. Res. Lett., 36, L09811, doi:10.1029/2008GL037124, 2009.

Marshak, A., Platnick, S., Várnai, T., Wen, G., and Cahalan, R. F.: Impact of three-dimensional radiative effects on satellite retrievals of cloud droplet sizes, J. Geophys. Res., 111, D09207, doi:10.1029/2005JD006686, 2006.

McComiskey, A. and Feingold, G.: The scale problem in quantifying aerosol indirect effects, Atmos. Chem. Phys., 12, 1031-1049, doi:10.5194/acp-12-1031-2012, 2012.

Mechoso, C., Wood, R., Bretherton, C. S., Clarke, A., Coe, H., Fairall, C., Farrar, J. T., Feingold, G., Garreaud, R., Grados, C., McWilliams, J., de Szoeke, S., Yuter, S., and Zuidema, P.: OceanCloud-Atmosphere-Land Interactions in the Southeast Pacific: The VOCALS Program, Bull. Amer. Meteor. Soc., in press, 2013.

Minnis, P., Sun-Mack, S., Trepte, Q. Z., Chang, F.-L., Heck, P. W., Chen, Y., Yi, Y., Arduini, R. F., Ayers, K., Bedka, K., Bedka, S., Brown, R., Gibson, S., Heckert, E., Hong, G., Jin, Z., Palikonda, R., Smith, R., Smith, W., Spangenberg, D., Yang, P., and Yost, C. X. Y.: CERES Edition 3 cloud retrievals, Proc. AMS 13th Conf. Atmos. Rad., Portland, OR, 27 June-2 July, 5.4, 2010.

Minnis, P., Sun-Mack, S., Young, D. F., Heck, P. W., Garber, D. P., Chen, Y., Spangenberg, D. A., Arduini, R. F., Trepte, Q. Z., Smith Jr., W. L., Ayers, J. K., Gibson, S. C., Miller, W. F., Chakrapani, V., Takano, Y., Liou, K.-N., and Xie, Y.: CERES Edition-2 cloud property retrievals using TRMM VIRS and Terra and Aqua MODIS data - Part I: Algorithms, IEEE Trans. Geosci. Remote Sens., 49, 4374-4400, doi:10.1109/TGRS.2011.2144601, 2011a.

Minnis, P., Sun-Mack, S., Chen, Y., Khaiyer, M. M., Yi, Y., Ayers, J. K., Brown, R. R., Dong, X., Gibson, S. C., Heck, P. W., Lin, B., Nordeen, M. L., Nguyen, L., Palikonda, R., Smith, W. L., Spangenberg, D. A., Trepte, Q. Z., and Xi, B.: CERES Edition2 Cloud Property Retrievals Using TRMM VIRS and Terra and Aqua MODIS Data - Part II: Examples of Average Results and Comparisons With Other Data, IEEE Trans. Geosci. Remote Sens., 49, 4401-4430, doi:10.1109/TGRS.2011.2144602, 2011 b. 
Nagao, T. M., Suzuki, K., and Nakajima, T. Y.: Interpretation of Multiwavelength-Retrieved Droplet Effective Radii for Warm Water Clouds in Terms of In-Cloud Vertical Inhomogeneity by Using a Spectral Bin Microphysics Cloud Model, J. Atmos. Sci., 70, 2376-2392, doi:10.1175/JAS-D-12-0225.1, 2013.

Nakajima, T. Y., Suzuki, K., and Stephens, G. L.: Droplet growth in warm water clouds observed by the A-Train. Part II: A multisensor view, J. Atmos. Sci., 67, 1897-1907, doi:10.1175/2010JAS3276.1, 2010.

O’Dell, C. W., Wentz, F. J., and Bennartz, R.: Cloud liquid water path from satellite-based passive microwave observations: A new climatology over the global oceans, J. Climate, 21, 1721-1739, 2008.

Painemal, D. and Zuidema P.: Assessment of MODIS cloud effective radius and optical thickness retrievals over the Southeast Pacific with VOCALS-Rex in-situ measurements, J. Geophys. Res., 116, D24206, doi:10.1029/2011JD016155, 2011.

Painemal, D., Minnis, P., Ayers, J. K., and O'Neill, L.: GOES-10 microphysical retrievals in marine warm clouds: Multi-instrument validation and daytime cycle over the southeast Pacific, J. Geophys. Res., 117, D19212, doi:10.1029/2012JD017822, 2012.

Painemal, D., Minnis, P., and O'Neill, L.: The diurnal cycle of cloud-top height and cloud cover over the Southeastern Pacific as observed by GOES-10, J. Atmos. Sci., 70, 2393-2408, doi:10.1175/JAS-D-12-0325.1, 2013.

Platnick, S.: Vertical photon transport in cloud remote sensing problems, J. Geophys. Res., 105, 22919-22935, doi:10.1029/2000JD900333, 2000.
Platnick, S., King, M., Ackerman, S., Menzel, W., Baum, B., Riedi, J., and Frey R.: The MODIS cloud products: Algorithms and examples from Terra, IEEE Trans. Geosci. Remote Sens., 41, 459473, doi:10.1109/TGRS.2002.808301, 2003.

Seethala, C. and Horváth, Á.: Global assessment of AMSR$\mathrm{E}$ and MODIS cloud liquid water path retrievals in warm oceanic clouds, J. Geophys. Res., 115, D13202, doi:10.1029/2009JD012662, 2010.

Stevens, B. and Brenguier, J.-L.: Cloud-controlling factors: low clouds, in: Clouds in the perturbed climate system, edited by: Heintzenberg, J. and Charlson, R., Cambridge, Mass.: MIT Press, 173-196, 2009.

Stubenrauch, C., Rossow W. B., Kinne, S., Ackerman S., Cesana G., Chepfer H., Di Girolamo L., Getzewich B., Guignard A., Heidinger A., Maddux B. C., Menzel W. P., Minnis P., Pearl C., Platnick S., Poulsen C., Riedi J., Sun-Mack S., Walther A., Winker D., Zeng S., and Zhao G.: Assessment of global cloud datasets from satellites: Project and database initiated by the GEWEX Radiation Panel, Bull. Am. Meteorol. Soc., 94, 10311049, doi:10.1175/BAMS-D-12-00117, 2013.

Wentz, F. and Meissner, T.: AMSR ocean algorithm, Algorithm Theor. Basis Doc. 121599A-1, Remote Sens. Syst., Santa Rosa, Calif., 2000.

Wood, R.: Stratocumulus clouds, Mon. Weather Rev., 140, 2373 2423, doi:10.1175/MWR-D-11-00121.1, 2012.

Zhang, Z. and Platnick, S.: An assessment of differences between cloud effective particle radius retrievals for marine water clouds from three MODIS spectral bands, J. Geophys. Res., 116, D20215, doi:10.1029/2011JD016216, 2011. 